\title{
Neuroimaging Risk Markers for Substance Abuse: Recent Findings on Inhibitory Control and Reward System Functioning
}

\author{
Mary M. Heitzeg ${ }^{1} \cdot$ Lora M. Cope $^{1} \cdot$ Meghan E. Martz $^{1,2} \cdot$ Jillian E. Hardee $^{1}$
}

Published online: 15 April 2015

(C) Springer International Publishing AG 2015

\begin{abstract}
Rates of alcohol and other drug use rise sharply throughout adolescence and peak in the early 20s. Likewise, prevalence of first-time substance use disorder (SUD) and past-year SUD both peak between ages 18-23. SUD is associated with a host of negative outcomes and is a serious health concern. Understanding the mechanisms that precede the onset and escalation of substance use is crucial in order to develop more effective prevention and intervention strategies for children and adolescents at risk for SUD. In this review, we discuss recent findings from functional neuroimaging studies in children, adolescents, and emerging adults that focus on uncovering the neural underpinnings of SUD risk. The focus is on inhibitory control and reward circuitry due to their involvement in risk-taking behaviors, which are heightened in adolescence and may facilitate substance use. We discuss convergences in the literature and highlight findings suggesting that the association between SUD risk and neurofunctioning
\end{abstract}

This article is part of the Topical Collection on Adolescent Substance Abuse

Mary M. Heitzeg

mheitzeg@umich.edu

Lora M. Cope

lcope@umich.edu

Meghan E. Martz

mmartz@umich.edu

Jillian E. Hardee

jhardee@umich.edu

1 Department of Psychiatry and Addiction Research Center, The University of Michigan, 4250 Plymouth Rd., Ann Arbor, MI 48109, USA

2 Department of Psychology, The University of Michigan, 2044 East Hall, 530 Church St., Ann Arbor, MI 48108, USA may be moderated by age, gender, and history of substance use. Recommendations for future directions are also discussed.

Keywords Substance abuse $\cdot$ Adolescents · Vulnerability · Neuroimaging $\cdot$ Inhibitory control $\cdot$ Reward processing · Ventral striatum $\cdot$ Nucleus accumbens $\cdot$ Addiction . Development

\section{Introduction}

Adolescence is a time of increased risky behaviors, including initiation and escalation of alcohol and other drug use [1-3]. Early substance use initiation is strongly associated with the development of a substance use disorder (SUD), with lifetime rates of alcohol dependence estimated at over $40 \%$ [4] and drug dependence at over $30 \%$ [5] among those who begin use by age 13. Parental SUD further raises risk for offspring SUD beyond risk conferred by age of first use $[4,5]$. SUD is a serious health concern, having been linked to a wide range of mental, physical, and social harms [6-8]. In order to develop more effective prevention and intervention strategies to reduce the morbidity and mortality associated with SUD, understanding the mechanisms that precede the onset and escalation of use is crucial.

Over the past decade, there has been an emergence of studies investigating the neural basis of risk for SUD using functional magnetic resonance imaging (fMRI), much of which has focused on the biological underpinnings of risk-taking behaviors that facilitate substance use. In general, these include neural mechanisms underlying inhibitory control, which involves executive functioning and can be considered a topdown system supporting behavioral control, and incentive reactivity, which responds to rewarding or salient stimuli and 
can be considered a more reactive, or bottom-up system [9-11]. This review summarizes recent findings (i.e., within the last 3 years) regarding neurofunctional risk markers for SUD in children, adolescents, and emerging adults, specifically in the domains of inhibitory control and reward responsiveness. There are many ways to approach the investigation of risk; we focus this review on family history, prospective, and imaging genetic studies. Gender effects, when analyzed, are noted. We discuss convergences in the literature and highlight findings suggesting that relationships between SUD risk and neurofunctioning may be moderated by age, gender, and history of substance use. Recommendations for future directions are also discussed.

\section{Inhibitory Control}

Poor inhibitory control is a key mechanism underlying behavioral undercontrol generally and vulnerability to disinhibitory psychopathology, such as substance abuse, more specifically [12]. In adolescents, impulsivity has been associated with earlier and greater substance use $[13,14]$ and SUD diagnosis [15]. Given the robust association between inhibitory control and risk for SUD, there has been great interest in uncovering the neural substrates that may mediate this relationship. The following sections review family history and prospective studies examining brain regions and circuits associated with response inhibition and substance use behavior.

\section{Family History Studies}

Two recent studies have examined the influence of family history on inhibitory circuitry. Silveri et al. [16] investigated the impact of parental alcohol use disorder (AUD) on brain activation during a Stroop task in healthy 8-19-year olds with fewer than four lifetime episodes of alcohol or drug use. During Stroop interference, youth with parental AUD $(\mathrm{FH}+)$ showed greater activation of the frontal network involved in response inhibition, including middle frontal and cingulate gyri, than youth without parental AUD (FH-). This was interpreted as reflecting compensatory mechanisms due to reduced neuronal efficiency of this network. In contrast, findings from earlier cross-sectional work in children and adolescents suggest that blunted frontal activation during inhibitory control may be an underlying factor in risk $[17,18]$ (although this was not apparent in a sample of late adolescents/emerging adults [19]). One reason for this difference may be that the Stroop task is more cognitively demanding than other inhibitory tasks, thereby unmasking functional differences under more effortful conditions. Furthermore, the ability to successfully inhibit a response increases from childhood into early adulthood [20], concomitant with maturation of inhibitory control circuitry [21]. Therefore, the use of a broad age range (8-19 years) may mask important developmental differences.

In order to address developmental differences in inhibitory control functioning among at-risk youth, Hardee et al. [22] used a longitudinal study design. Youth entered the study at $7-12$ years of age and underwent 1-3 follow-up scans at 1 - to 2 -year intervals, covering the age range of 7-17 years. Inhibitory control was probed with a go/no-go task, which engages individuals in responding to frequent "go" signals and requires them to inhibit a prepotent response when infrequent "no-go" signals occur. Significant age-by-group interactions were found in right caudate, middle cingulate, and middle frontal gyrus during successful no-go trials. At baseline, when participants were 7-12 years old and had minimal substance use, $\mathrm{FH}+$ youth had blunted activation in each of these regions compared with $\mathrm{FH}-$ youth, consistent with prior evidence [17, 18]. With age, activation decreased in the caudate and middle frontal gyrus in FH- youth only, suggesting a normal developmental pattern absent in high-risk youth. In contrast, $\mathrm{FH}+$ youth demonstrated increased middle cingulate activation with age, interpreted as a compensatory mechanism for a weakness or developmental delay in response inhibition circuitry; thus, more effort may be required in high-risk youth to overcome the prepotent automatic response generated in the go/no-go task.

\section{Prospective Studies}

A recent emergence of prospective neuroimaging studies has identified early-occurring brain functional differences during inhibitory control tasks that differentiate youth who do and do not go on to problem substance use. Using baseline fMRI data as a predictor of later substance use or problems, prospective studies provide a more definitive connection between neural activation patterns and risk than possible with family history studies.

\section{Blunted Activation During Inhibitory Control as a Risk Marker for Problem Substance Use}

Norman et al. [23•] scanned 12-14-year olds with minimal substance use during a go/no-go task and categorized them as heavy drinkers or controls approximately 4 years later. Youth who transitioned into heavy alcohol use displayed blunted neural activation during no-go trials at baseline, prior to the onset of use, in widespread regions of inhibitory control circuitry, including the frontal, parietal, and temporal cortices and striatum. More recently, Mahmood et al. [24] scanned high- and low-frequency substance users between the ages of 16-19 years during a go/no-go task to investigate whether activation during no-go trials predicted use and dependence symptoms 18 months later. Less ventromedial prefrontal activation predicted more drug and alcohol dependence 
symptoms at follow-up, above and beyond baseline symptoms and lifetime drug use, particularly in high-frequency users. In contrast, increased engagement of the left angular and supramarginal gyri during no-go trials predicted more total drug use occasions in the follow-up period, again, an effect most evident in high-frequency users. The left angular and supramarginal gyri are not commonly associated with inhibitory control $[25,26]$; thus, the authors suggest that, in order to achieve comparable performance, these youth may use an alternate strategy to compensate for a relative weakness in cognitive control. It is unclear from this work whether the emergence of heightened risk-related activation is a developmental effect related to the older age of participants (e.g., compared to $[18,23 \cdot])$ as the work of Hardee et al. might suggest [22], or whether this activation is due to the inclusion of high-frequency substance users.

Recent longitudinal work by Wetherill et al. [27•] suggests that the initiation of heavy substance use during adolescence may result in less efficient response inhibition circuitry, marked by heightened activation. Baseline fMRI data was acquired during the go/no-go task in 11-16-year olds with minimal substance use and again approximately 3 years later after grouping them into heavy drinkers and demographically matched non-drinking controls. At baseline, youth who later became heavy drinkers showed blunted activation in the bilateral middle frontal gyrus, right inferior parietal lobule, left putamen, and left cerebellum during no-go trials, consistent with prior work $[18,22,23 \cdot 24]$. At follow-up, however, these same youth showed greater activation in each region (excluding the putamen). Therefore, blunted inhibitory control functioning may be associated with risk prior to heavy substance use, whereas after heavy use is initiated, inefficient neural recruitment may begin to play a larger role.

\section{Brain Functioning During Inhibitory Errors as a Risk Marker for Problem Substance Use}

Error processing is critical for adaptive adjustment of performance and thus is an important aspect of inhibitory control [28]. Much of the work using the go/no-go task to investigate familial risk either focuses on successful trials only $[19,22]$ or does not differentiate between successful and failed no-go trials [18, 23• 24, 27•]. Recent work by Heitzeg et al. [29] extends this literature by differentiating between successful and failed inhibitory (no-go) trials. Participants underwent a baseline scan at age 9-12 years, and those who demonstrated problem substance use by age 13-16 were matched on age, gender, and parental AUD to substance-naïve controls. No baseline activation differences were observed between groups during successful no-go trials. However, those who went on to have problem substance use demonstrated blunted activation in the left middle frontal gyrus to inhibitory errors (failed nogo trials) compared with controls at baseline. Blunted activation to errors in this region at age 9-12 was associated with more externalizing problems at age 11-13 and predicted problem substance use by age 13-16 over and above externalizing problems. Although this sample consisted primarily of males, exploratory analyses revealed that all effects trended in the same direction among females. Thus, blunted activation in error monitoring circuitry at an early age may underlie problems adapting behavior appropriately, leading to undercontrolled behavior and early problem substance use.

Work from IMAGEN, a large-scale longitudinal study of adolescent development [30], has also identified brain functioning during failed inhibition as one important risk factor for problem substance use $[31 \bullet \bullet$. Using machine learning, models of risk were generated incorporating a broad range of factors including personality, life experience, cognition, genetics, brain structure, and brain function. Magnitude of prefrontal activation to inhibitory errors during a stop signal task at age 14 was one significant predictor of binge drinking by age 16 .

\section{Summary}

The studies reviewed above are summarized in Table 1. Taken together, evidence indicates that in childhood and early adolescence, a blunting of response inhibition circuitry is a risk factor for later problem substance use, whereas more complex patterns emerge later in adolescence as inhibitory control circuitry matures and heavy substance use begins. The evidence converges on risk-related effects in the prefrontal cortex with findings specifically in the middle frontal gyrus common across all studies (with one exception [24]). Results are less consistent regarding other inhibitory control regions. Methodical issues likely contribute to this variability; most studies (with two exceptions [16, 31••]) used a variation of the go/ no-go task, yet timing and designs differed across studies and the specific data used in analyses varied based on whether fixation, go trials, or implicit baselines were used and whether successful and failed no-go trials were differentiated.

An emerging literature describes an impact of genetic variation in dopamine signaling on prefrontal cortical function during inhibitory control in typically developing adolescents [32] and young adults [33], and on impulsivity [34] and drug craving [35] in adults. However, thus far, there have been no studies investigating specific relationships among genetic variation, neural functioning during inhibitory control, and risk for problem substance use in children, adolescents, or emerging adults. This will be an important direction for future research.

Gender differences were investigated directly in only one study [29], as an exploratory analysis with a small sample of females. No suggestion of a gender difference in the relationship between brain mechanisms involved in inhibitory control and early risk for problem substance use was found in this 9- 
Table 1 Summary of primary findings in the domains of inhibitory control and reward sensitivity from family history, imaging genetic and prospective studies of risk for substance use disorder in children, adolescents and emerging adults

\begin{tabular}{|c|c|c|c|c|}
\hline Study & Design & Participants & fMRI task & Main findings \\
\hline \multicolumn{5}{|l|}{ Inhibitory control } \\
\hline \multicolumn{5}{|l|}{ Family history } \\
\hline Silveri 2011 [16] & $\begin{array}{l}\text { Cross-sectional; } \\
\text { Parental AUD }\end{array}$ & $\begin{array}{l}n=32 \\
\text { Ages } 8-19 ; \\
59 \% \text { female }\end{array}$ & Stroop & $\begin{array}{l}\text { During stroop interference: } \mathrm{FH}+>\mathrm{FH}^{-} \\
\text {activation in frontal inhibition network, } \\
\text { including middle frontal and cingulate gyri. }\end{array}$ \\
\hline Hardee 2014 [22] & $\begin{array}{l}\text { Longitudinal; } \\
2-4 \text { scans per subject; } \\
\text { Parental AUD }\end{array}$ & $\begin{array}{l}n=73 ; \\
\text { Baseline age 7-12; Age } \\
\quad \text { range } 7-19 ; \\
30 \% \text { female }\end{array}$ & Go/No-Go & $\begin{array}{l}\text { Successful no-go trials: Age-by-group } \\
\text { interaction found: } \\
\text { At baseline (ages 7-12): FH }+<\text { FH- activation in } \\
\text { R caudate middle cingulate, middle frontal } \\
\text { gyrus; } \\
\text { With age: FH- youth showed decreased } \\
\text { activation in caudate and middle frontal gyrus, } \\
\text { not seen in FH+ youth; FH+ youth showed } \\
\text { increased middle cingulate activation with } \\
\text { age, not seen in FH- youth. }\end{array}$ \\
\hline \multicolumn{5}{|l|}{ Prospective } \\
\hline Norman 2011 [23] & $\begin{array}{l}\text { Prospective; } \\
\text { 4-yr follow-up; } \\
\text { Heavy drinking }\end{array}$ & $\begin{array}{l}n=38 \\
\text { Ages } 12-14 ; \\
50 \% \text { female }\end{array}$ & Go/No-Go & $\begin{array}{l}\text { No-go trials and heavy drinking: Those who } \\
\text { transitioned to heavy alcohol use showed } \\
\text { widespread blunted activation-in frontal } \\
\text { (including middle frontal gyrus), parietal, } \\
\text { temporal cortices and striatum - at baseline. }\end{array}$ \\
\hline Mahmood 2013 [24] & $\begin{array}{l}\text { Prospective; } \\
\text { 18-mo follow-up; } \\
\text { Dependence symptoms }\end{array}$ & $\begin{array}{l}n=80 ; \\
\text { Ages } 16-19 ; \\
29 \% \text { female }\end{array}$ & Go/No-Go & $\begin{array}{l}\text { No-go trials and dependence symptoms/ } \\
\text { substance use: In youth who were high- } \\
\text { frequency substance users at baseline--less } \\
\text { vmPFC activation predicted more dependence } \\
\text { symptoms at } 18 \text {-month follow-up and } \\
\text { increased activation in L angular and } \\
\text { supramarginal gyri predicted more drug use } \\
\text { occasions at follow-up. }\end{array}$ \\
\hline Wetherill 2013 [27] & $\begin{array}{l}\text { Prospective \& } \\
\text { longitudinal; } \\
\text { 2nd scan at 3-yr follow- } \\
\text { up; } \\
\text { Heavy drinking }\end{array}$ & $\begin{array}{l}n=40 ; \\
\text { Ages } 11-16 ; \\
45 \% \text { female }\end{array}$ & Go/No-Go & $\begin{array}{l}\text { No-go trials before and after heavy drinking: At } \\
\text { baseline, those who would become heavy } \\
\text { drinkers had blunted activation in bilateral } \\
\text { middle frontal gyrus, R inferior parietal lobule, } \\
\text { L putamen, L cerebellum; at follow-up, heavy } \\
\text { drinkers had greater activation in these regions } \\
\text { (except putamen). }\end{array}$ \\
\hline Heitzeg 2014 [29] & $\begin{array}{l}\text { Prospective; } \\
\text { 4-yr follow-up; } \\
\text { Problem substance use }\end{array}$ & $\begin{array}{l}n=45 ; \\
\text { Ages } 9-12 ; \\
22 \% \text { female }\end{array}$ & Go/No-Go & $\begin{array}{l}\frac{\text { Successful no-go and problem substance use: No }}{\text { differences between problem users and }} \\
\text { controls. } \\
\text { Inhibitory errors and problem substance use: } \\
\text { (failed no-go trials): Problem users < controls } \\
\text { in L middle frontal gyrus. Blunted activation } \\
\text { in this area at baseline predicted problem } \\
\text { substance use at follow-up. }\end{array}$ \\
\hline Whelan 2014 [31] & $\begin{array}{l}\text { Prospective; } \\
\text { 2-yr follow-up; } \\
\text { Binge drinking }\end{array}$ & $\begin{array}{l}n=692 ; \\
\text { Age } 14 ; \\
52 \% \text { female }\end{array}$ & Stop signal & $\begin{array}{l}\text { Inhibitory errors and binge drinking: Greater } \\
\text { activation in right middle, medial and } \\
\text { precentral gyri and left postcentral and middle } \\
\text { frontal gyri at } 14 \text { predicted binge drinking by } \\
\text { age } 16 .\end{array}$ \\
\hline
\end{tabular}

Reward sensitivity

Family history

Stice 2014 [47]

$\begin{aligned} \text { Cross-sectional; } & n=52 ; \\ \text { Parental SUD } & \text { Ages } 14-17 ; \\ & 52 \% \text { female }\end{aligned}$

Coin flip

Reward anticipation: $\mathrm{FH}+>\mathrm{FH}$ - activation in $\mathrm{L}$ dlPFC cortex and bilateral putamen; $\mathrm{FH}+<$ $\mathrm{FH}-$ activation in fusiform gyrus and inferior temporal gyrus. 
Table 1 (continued)

\begin{tabular}{|c|c|c|c|c|}
\hline Study & Design & Participants & fMRI task & Main findings \\
\hline Yau 2012 [52] & $\begin{array}{l}\text { Cross-sectional; } \\
\text { Parental AUD }\end{array}$ & $\begin{array}{l}n=40 \\
\text { Ages } 18-22 \\
40 \% \text { female }\end{array}$ & $\begin{array}{l}\text { Monetary } \\
\text { incentive delay }\end{array}$ & $\begin{array}{l}\text { Reward anticipation: Drinking-by-FH interaction } \\
\text { with light drinking } \mathrm{FH}+<\text { heavy drinking FH+ } \\
\text { and } \mathrm{FH}-\text { in NAcc; no differences in NAcc } \\
\text { activation between heavy drinking } \mathrm{FH}+\text { and } \\
\text { FH-. } \\
\text { NAcc activation positively correlated with } \\
\text { drinking in } \mathrm{FH}+\text { only. }\end{array}$ \\
\hline Muller 2014 [55] & $\begin{array}{l}\text { Cross-sectional; } \\
\text { Parental AUD }\end{array}$ & $\begin{array}{l}n=412 ; \\
\text { Ages } 13-15 \\
49 \% \text { female }\end{array}$ & $\begin{array}{l}\text { Monetary } \\
\text { incentive delay }\end{array}$ & $\begin{array}{l}\text { Reward anticipation and outcome: } \\
\text { differences in activation between } \mathrm{FH}+\text { and } \\
\text { FH-. }\end{array}$ \\
\hline Ivanov 2012 [64] & $\begin{array}{l}\text { Cross-sectional; } \\
\text { Parental SUD }\end{array}$ & $\begin{array}{l}n=20 \\
\text { Ages } 8-13 \\
10 \% \text { female; } \\
\text { All ADHD }\end{array}$ & $\begin{array}{l}\text { Anticipation- } \\
\text { conflict-reward }\end{array}$ & $\begin{array}{l}\frac{\text { Reward anticipation and outcome: } \mathrm{FH}+>\mathrm{FH}-}{\text { activation in motivational-reward circuitry, }} \\
\text { including L anterior insula/caudate, } \mathrm{L} \text { inferior } \\
\text { frontal gyrus, L OFC. } \\
\text { Cognitive conflict: FH+ }<\text { FH- activation in } \\
\text { behavioral inhibition circuitry, including right } \\
\text { anterior cingulate cortex, L dmPFC. }\end{array}$ \\
\hline Cservenka 2012 [65] & $\begin{array}{l}\text { Cross-sectional; } \\
\text { Parental AUD }\end{array}$ & $\begin{array}{l}n=31 \\
\text { Ages } 13-15 \\
35 \% \text { female }\end{array}$ & Wheel of fortune & $\begin{array}{l}\text { Risky choices: } \mathrm{FH}+<\mathrm{FH} \text { - activation in dIPFC } \\
\text { and cerebellum. }\end{array}$ \\
\hline Cservenka 2014 [67] & $\begin{array}{l}\text { Cross-sectional; } \\
\text { Parental AUD }\end{array}$ & $\begin{array}{l}n=97 \\
\text { Ages } 10-16 \\
44 \% \text { female }\end{array}$ & Resting state & $\begin{array}{l}\text { Intrinsic NAcc connectivity: } \mathrm{FH}+<\mathrm{FH}- \\
\text { segregation between L NAcc and bilateral } \\
\text { inferior frontal gyri (reduced segregation } \\
\text { showed trend association with sensation- } \\
\text { seeking); FH+ had negative functional } \\
\text { connectivity between R NAcc and L OFC, } \\
\text { whereas FH- had positive functional } \\
\text { connectivity. }\end{array}$ \\
\hline Weiland 2013 [68] & $\begin{array}{l}\text { Cross-sectional; } \\
\text { Parental AUD }\end{array}$ & $\begin{array}{l}n=70 \\
\text { Ages } 18-22 \\
33 \% \text { female }\end{array}$ & $\begin{array}{l}\text { Monetary } \\
\text { incentive delay }\end{array}$ & $\begin{array}{l}\text { NAcc connectivity during incentive anticipation: } \\
\text { NAcc connectivity with attention, motor, and } \\
\text { default mode network regions was decreased } \\
\text { in FH- but increased in FH+; connectivity } \\
\text { strength mediated the relation between } \\
\text { sensation-seeking and alcohol use in FH+. }\end{array}$ \\
\hline
\end{tabular}

Imaging genetics

Nikolova 2013 [75••] Cross-sectional; GAL5.1

Villafuerte 2012 [76] Cross-sectional; GABRA2

Heitzeg 2014 [57•] Longitudinal; 1-4 scans per subject; GABRA2

Prospective

$\begin{array}{ll}\text { Heitzeg 2014 [57•] } & \text { Prospective; } \\ & \text { 4-yr follow-up; } \\ & \text { Alcohol problems }\end{array}$

$n=138$;

Mean age 19;

$52 \%$ female;

College students

$n=44$;

Ages 18-22;

$45 \%$ female

$n=175$;

Baseline age 8-13 \&

18-23;

Age range 8-27;

$30 \%$ female

$n=104$;

Ages 8-13, 18-23; $30 \%$ female
Number guessing

GAL5.1 and VS reactivity: Genotype-by-gender interaction for activation in VS (male CA > female CA; female GG > female CA). Gender differences in VS activation as a mediator of genotype and problem drinking.

Monetary
incentive delay

$\underline{G A B R A 2}$ and insula activation: During reward anticipation, risk allele $(\mathrm{G})$ homozygotes had greater activation in L insula, significant only in females. GG genotype and insula activation associated with impulsivity across all subjects.

Monetary incentive delay

GABRA2 and NAcc reactivity: Age-by-genotype interaction where $\mathrm{G}$ carriers (GG and $\mathrm{AG}$ ) had higher NAcc activation to reward anticipation in adolescence (not childhood or young adulthood); AA showed no age-related changes.

Monetary
incentive delay

NAcc activation and alcohol problems: Increased NAcc activation during reward anticipation was associated with more alcohol problems over 3-5 years of follow-up. 
Table 1 (continued)

\begin{tabular}{|c|c|c|c|c|}
\hline Study & Design & Participants & fMRI task & Main findings \\
\hline Dager 2014 [82] & $\begin{array}{l}\text { Prospective; } \\
\text { 1-yr follow-up; } \\
\text { Transition to heavy } \\
\quad \text { drinking }\end{array}$ & $\begin{array}{l}n=43 \\
\text { Ages } 18-21 ; \\
53 \% \text { female }\end{array}$ & $\begin{array}{l}\text { Pictorial cue } \\
\text { reactivity } \\
\text { (alcohol/non- } \\
\text { alcohol } \\
\text { pictures) }\end{array}$ & $\begin{array}{l}\text { Cue-reactivity and heavy drinking: Transitioners } \\
\text { to heavy drinking had greater response to } \\
\text { alcohol vs. non-alcohol pictures in cue- } \\
\text { reactive circuitry (caudate, vmPFC, anterior } \\
\text { cingulate, OFC, insula); greater reactivity of } \\
\text { this circuitry predicted more alcohol } \\
\text { involvement over 1-yr follow-up. }\end{array}$ \\
\hline Whelan 2014 [31••] & $\begin{array}{l}\text { Prospective; } \\
\text { 2-yr follow-up; Binge } \\
\quad \text { drinking }\end{array}$ & $\begin{array}{l}n=692 ; \\
\text { Age 14; } \\
52 \% \text { female }\end{array}$ & $\begin{array}{l}\text { Monetary } \\
\text { incentive delay }\end{array}$ & $\begin{array}{l}\text { Reward and binge drinking: Activations at age } \\
14 \text { predicted binge drinking at age } 16: \text { reduced } \\
\text { activation in occipito-temporal and posterior } \\
\text { cingulate regions during reward anticipation; } \\
\text { increased activation in superior frontal gyrus } \\
\text { and reduced activation in left temporal pole } \\
\text { during reward outcome. }\end{array}$ \\
\hline
\end{tabular}

Studies are termed "prospective" if neuroimaging data from one time point are used to differentiate youth based on a later substance use outcome. Studies are termed "longitudinal" if neuroimaging data are collected at more than one time point. For prospective studies, age range in participant column refers to scan time. For longitudinal studies, age range in participant column refers to 1 st scan time

$F H+$ family history positive, $F H$ - family history negative, $A U D$ alcohol use disorder, $S U D$ substance use disorder, $A D H D$ attention deficit hyperactivity disorder, $L$ left, $R$ right, mo month, $y r$ year, $N A c c$ nucleus accumbens, $O F C$ orbitofrontal cortex, $V S$ ventral striatum, $v m P F C$ ventromedial prefrontal cortex, $d l P F C$ dorsolateral prefrontal cortex, $d m P F C$ dorsomedial prefrontal cortex

12-year-old sample; however, evidence in adults indicates that increased thalamic activation during inhibitory errors uniquely marks parental risk in males but not females [36]. Further work is required investigating gender differences in children and adolescents prior to the onset of significant substance use to determine whether early-occurring neural functioning of inhibitory control systems may relate to risk for SUD differently in males and females.

\section{Reward Sensitivity}

Reward sensitivity is especially pronounced during adolescence, aligning with developmental increases in sensationseeking and substance use that occur during this period [2, 37]. The peak in reward sensitivity during adolescence is associated with reorganization of the dopaminergic system, including projections from the limbic to the prefrontal system $[37,38]$. The mesolimbic dopamine system is critical to incentive processing [39], is centrally involved in the reinforcing properties of drugs of abuse [40], and has been implicated in vulnerability to addiction [41-43]. Thus, reward system functioning has emerged as an important target in the study of neurofunctional risk markers for SUD. There are competing views, however, regarding the relationship between reward functioning and risk; some hypotheses propose a hyperresponsive system biases individuals toward heightened reward-seeking leading to increased substance use (e.g., [44, 45]), whereas others propose a hypo-responsive system motivates individuals to seek out strong rewards such as drugs to raise the system to normal levels [46]. The following sections review family history, imaging genetic, and prospective studies of the association between reward functioning and substance use behavior.

\section{Family History Studies}

\section{Regional Brain Activation in Response to Reward Cues}

Several recent studies have investigated the influence of family history on reward system function with mixed evidence for reward-related SUD-risk markers. Stice and Yokum [47] used a coin flip task in 14-17-year olds to study how parental SUD influences the neural circuitry involved in monetary reward anticipation. Participants were matched on gender and had not used substances in the previous year. $\mathrm{FH}+$ youth displayed greater activation in the left dorsolateral prefrontal cortex and bilateral putamen and less activation in the fusiform gyrus and inferior temporal gyrus relative to $\mathrm{FH}^{-}$youth, suggesting that at-risk youth exhibit increased responsiveness but also greater attentional disengagement during reward anticipation. These results support a reward-surfeit model of addiction, whereby those at risk have increased reward system sensitivity. A limitation, however, is the lack of lifetime substance use characterization in the groups. Even in a non-addicted sample, prior drug exposure may modulate reward circuitry response $[48,49]$, and $\mathrm{FH}+$ youth would be expected to have more lifetime substance use [50, 51].

Yau et al. [52] investigated how parental AUD impacts reward system function in 18-22-year olds who were individually matched across family history groups on lifetime and current substance use, as well as age and gender. The focus 
was specifically on nucleus accumbens (NAcc) activation during a monetary incentive delay task (MIDT) [53]. The MIDT is a well-validated task used to study neural circuitry involved in incentive reactivity; it has been associated with robust ventral striatal (VS) activation, including the NAcc [54]. Overall, the $\mathrm{FH}+$ group demonstrated blunted NAcc activation during reward anticipation compared with $\mathrm{FH}-$ youth. However, uniquely within the $\mathrm{FH}+$ group, NAcc activation positively correlated with earlier externalizing behaviors and current and lifetime amounts of drinking, which belies a simple interpretation relating hypo-activation to SUD risk. Instead, links among heightened NAcc responsivity, substance use, and behavioral risk may underlie vulnerability uniquely in $\mathrm{FH}+$ youth [52]. When investigating heavy versus light drinkers within each group, an interaction between family history and alcohol use was revealed. Specifically, light-drinking $\mathrm{FH}+$ youth had blunted activation compared with their heavydrinking $\mathrm{FH}+$ counterparts as well as compared with all $\mathrm{FH}^{-}$ youth. In contrast, heavy-drinking $\mathrm{FH}+$ youth did not differ from $\mathrm{FH}^{-}$youth. The authors suggest that this blunted NAcc response in light-drinking $\mathrm{FH}+$ youth reflects a resilience mechanism.

Interestingly, in a younger sample, Muller et al. [55] found no differences in activation to reward anticipation or receipt during the MIDT in AUD FH+ versus $\mathrm{FH}^{-}$youth. They investigated a large sample of 13-15-year olds, matched on gender and with similar levels of substance use across groups. This finding is consistent with prior work reporting no differences in NAcc activation during the MIDT in 12-16-year-old AUD FH+ and $\mathrm{FH}^{-}$groups [56]. As the authors noted, it is possible that conferment of familial risk related to reward responsivity emerges later in development [55]. Indeed, some evidence exists for changes in risk-related activation of NAcc to reward across development [57•], described below. However, it is likely that other methodological differences also play a role in discrepant results across studies, such as task design and timing, and subject-selection criteria, including levels of prior substance use and psychopathology.

\section{Functional Imbalance of Reward and Control Regions}

Of major significance to adolescent substance use is evidence suggesting that the relatively early maturation of subcortical incentive-reactive systems compared with later-maturing prefrontal control systems may bias adolescents toward seeking out reward [58-61]. This bias is proposed to underlie the impulsive, risky decision-making associated with adolescence $[62,63]$ and may also contribute to heightened risk for SUD; this has been the focus of several recent studies. Ivanov et al. [64] studied drug-naïve 8-13-year olds, primarily male, all with attention deficit/hyperactivity disorder (ADHD) and half with at least one parent with an SUD. An anticipationconflict-reward task was used, which includes both reward and executive control components. $\mathrm{FH}+$ youth had greater activity in motivational-reward circuitry, including left anterior insula (extending into caudate), left inferior frontal gyrus, and left orbitofrontal cortex, in response to reward anticipation and notification compared with $\mathrm{FH}^{-}$youth. $\mathrm{FH}+$ youth also showed less activity in behavioral inhibition circuitry, including right anterior cingulate cortex and left dorsomedial prefrontal cortex, during cognitive conflict. This study supports the hypothesis that SUD risk is related to a functional imbalance between reward and control areas.

Further support for a model of functional imbalance comes from work by Cservenka and Nagel [65], who investigated brain functioning during reward-related decision-making in 13-15-year-old AUD FH+ and FH- youth with minimal substance use. Risk taking in the context of high- and lowprobability reward was examined using a Wheel of Fortune task [66]. Despite comparable risk-taking behavior between groups, activation in dorsolateral prefrontal cortex and cerebellum was blunted during risky choices in $\mathrm{FH}+$ compared with $\mathrm{FH}-$ youth, suggesting reduced cognitive control during risky decision-making in at-risk youth.

\section{Connectivity Studies of the Balance Between Reward and Control Circuitry}

Two recent connectivity studies also lend support to riskrelated differences in the balance between reward and control circuitry. Using resting-state fMRI, Cservenka et al. [67] explored the intrinsic connectivity of the NAcc in 10-16-yearold AUD FH+ and $\mathrm{FH}^{-}$youth with minimal substance use. $\mathrm{FH}+$ youth had reduced segregation between the left NAcc and bilateral inferior frontal gyri compared with $\mathrm{FH}-$ youth; reduced segregation was associated with increased sensationseeking at a trend level. $\mathrm{FH}+$ youth also had negative functional connectivity between the right NAcc and left orbitofrontal cortex, whereas $\mathrm{FH}-$ subjects had positive functional connectivity. This suggests that, in at-risk youth, cognitive control and reward networks are not appropriately dissociated, and appetitive brain regions are not appropriately integrated [67]. This is one of the few studies that investigated a possible moderating influence of gender; however, no significant effect was observed.

Weiland et al. [68] probed the impact of parental AUD on task-related functional connectivity of the NAcc during the MIDT in 18-22-year olds. Substance use history did not differ significantly between risk groups. During incentive anticipation, NAcc connectivity with attention, motor, and default mode network regions-including paracentral lobule/ precuneus and sensorimotor areas-was decreased in $\mathrm{FH}-$ but increased in $\mathrm{FH}+$ youth. In $\mathrm{FH}+$ youth only, connectivity with NAcc in these regions correlated positively with sensation-seeking as well as drinking volume; the strength of connectivity significantly mediated the relationship 
between sensation-seeking and drinking volume. The authors suggest that differences in NAcc coupling with attention and motor networks may increase risk by influencing motor output in response to incentive cues. Though generally in line with the aforementioned studies, no differences were observed between groups in NAcc coupling with prefrontal cognitive control regions specifically. Instead, this finding is suggestive of more widespread network connectivity dysfunction in high-risk youth than what is predicted by a circumscribed model of imbalance between reward and cognitive control areas.

\section{Imaging Genetic Studies}

An emerging literature describes an impact of genetic variation in dopamine signaling on reward-related brain function in healthy adults [69-72]. There has been recent interest in investigating how genetic influences on reward system functioning may contribute to risk for problem substance use. The following paragraphs review associations of $G A L$ and GABRA2 in relation to fMRI reward response and substance use behavior in children and emerging adults.

\section{GAL, Reward Processing, and Risk for Problem Substance Use}

Galanin is a neuropeptide that has been linked to appetitive and consummatory behaviors, including drinking alcohol, via dopamine stimulation in the VS [73, 74]. Nikolova et al. [75••] tested the association between VS reactivity and a common functional haplotype (GAL5.1) of a gene coding for galanin $(G A L)$ in 138 college students (mean age 19.8 years) using a number-guessing paradigm. Positive feedback during this task elicits significant reward-related VS activity [72]. The GG haplotype, associated with higher GAL promoter activity, was hypothesized to be associated with greater VS reactivity and greater problem drinking than the CA haplotype; however, there was no direct effect of GAL5.1 haplotype on VS reactivity or problem drinking. A genotype-bygender interaction did emerge, however, with male CA carriers having higher VS activation than female CA carries, and female GG homozygotes higher than female CA carriers. Furthermore, reduced VS reactivity mediated an association between CA haplotype and lesser problem drinking in women, whereas in men, increased VS reactivity mediated the association between the CA haplotype and greater problem drinking. This novel work supports a role of galanin signaling within reward pathways in risk for problem substance use and also highlights an important gender difference in how this risk may unfold.
GABRA2, Reward Processing, and Risk for Problem Substance Use

Two recent studies focused on the impact of GABRA2 on reward processing in relationship to SUD risk $[57 \cdot, 76]$. The GABRA2 gene encodes the $\alpha 2$ subunit of the $\gamma$-aminobutyric acid A receptor $\left(\mathrm{GABA}_{\mathrm{A}}\right)$. This subunit is among the predominant receptor subtypes expressed in the NAcc [77] and contributes to inhibitory regulation of NAcc dopaminergic function [78]. Associations have been found between GABRA2 and adult AUD (e.g., $[79,80])$ as well as phenotypic precursors to SUD [81]. Villafuerte et al. [76] demonstrated an association between GABRA2 and brain function during the MIDT in 18-22-year olds; those homozygous for the risk allele $(G)$ showed heightened left insula activation during reward anticipation and were more likely to have alcohol dependence symptoms. Post hoc analysis revealed the effect was significant only in females. Both GG genotype and insula activation during reward anticipation were linked to impulsive behavior across the entire sample.

More recently, Heitzeg et al. [57•] examined the influence of GABRA2 on the developmental trajectory of NAcc activation during the MIDT longitudinally. Participants were 76 children (ages 8-13) and 99 emerging adults (ages 18-23) at study entry; $79 \%$ were AUD FH+, characteristic of a highrisk sample. The majority underwent repeated scanning at 1to 2-year intervals, covering the age range of 8-27. Substance use did not significantly differ by genotype but was used as a covariate to account for greater use with age. A significant age-by-genotype effect was observed whereby risk (G) allele carriers (GG and AG) had heightened NAcc activation to reward anticipation during adolescence but not childhood or young adulthood. In contrast, A homozygotes showed no significant age-related changes. During adolescence, G homozygotes showed significantly greater NAcc activation than A homozygotes, an effect that was not apparent in childhood or young adulthood. Supplementary analyses did not reveal any significant effects of gender. These findings support the view that reward-related SUD risk may be developmentally modulated (e.g., [55]) and represent an important step toward understanding genetic and neural influences underlying the unfolding of risk for SUD across development.

\section{Prospective Studies}

To date, there are no reports investigating whether earlyoccurring brain functional differences during reward, prior to significant substance use, can differentiate youth who do and do not go on to problem substance use. However, three prospective studies have examined relationships between reward circuitry functioning and later problem substance use in already-using samples. 
In the same study described previously, Heitzeg et al. [57•] found that increased NAcc activation to reward anticipation during the MIDT was positively associated with the number of alcohol-related problems reported over the next 3-6 years, even when controlling for lifetime drinking at time of the scan. Furthermore, mediation analysis revealed there was a significant indirect effect of GABRA2 genotype on later alcohol problems that was transmitted through NAcc activation.

A prospective study by Dager et al. [82] examined the relationship between the neural response to alcohol pictures and escalation of drinking over the following year in 18-21year-old college students. Participants were categorized into three groups based on alcohol use patterns at baseline and follow-up assessments: continuously moderate drinkers, continuously heavy drinkers, and transitioners from moderate to heavy drinking. Transitioners had a heightened response to alcohol versus non-alcohol pictures within cue-reactive circuitry (e.g., [83]), including the caudate, ventromedial prefrontal cortex, anterior cingulate, orbitofrontal cortex, and insula. Greater reactivity of this circuitry predicted increased drinking and more alcohol-related problems, beyond baseline level of drinking and self-reported impulsivity. Exploratory analyses found no effects of gender. This supports a model whereby enhanced motivation for alcohol or other drugs over-engages networks involved in reward and motivation [84]. Together, both the Heitzeg et al. [57•] and Dager et al. [82] studies suggest that heightened activity in reward networks early in an individual's substance-using "career" may mark those at the greatest risk for future problem use.

A third prospective study reported by Whelan et al. [31 ••] found that heightened activation in superior frontal gyrus to reward outcome during the MIDT at age 14 was one of several significant predictors of binge drinking by age 16 in the IMAGEN sample. These findings lend further support to the view that heightened activity in reward networks can signal future risk. However, these authors also reported a contribution of reduced activation in posterior regions not typically associated with reward responding to risk for later binge drinking.

\section{Summary}

The studies reviewed above are summarized in Table 1. Taken together, the bulk of evidence supports a relationship between hyperactive neural responses in reward-related circuitry and risk for SUD. This was supported by family history studies $[47,52,64]$, imaging genetic studies [57•, 75••, 76], and prospective studies $[31 \bullet, 57 \bullet, 82]$, and some evidence indicates the effect may be developmentally modulated [57•]. There is also some suggestion that reduced activation to reward in posterior regions, including occipital and temporal cortices and posterior cingulate, may be a risk factor for SUD [31••,
47], possibly reflecting abnormal processing of, and/or attention to, rewarding stimuli. Furthermore, accumulating evidence suggests that a functional imbalance between reward and control areas may contribute to risk-related hyperactivity of reward system functioning [64, 67, 68], which converges with findings of weakness in inhibitory control mechanisms in at-risk youth. There is some indication of gender differences in these brain functional pathways to risk (e.g., [75••, 76]), although others found no effects [57•, 67, 82], and most studies did not explore gender differences.

\section{Conclusions and Directions for Future Research}

The development of SUD is a multistage process, beginning with alcohol or drug experimentation, followed by more frequent use, and finally for a subset of users, compulsive use. Peak 12-month prevalence of SUD occurs between ages 18 and $23[85,86]$. Therefore, for many, as this cascade of risk unfolds, significant developmental changes are also occurring in personality, behavior, and socialization, and in brain structure and function. Individual differences in cognitive control and reward responsive circuitry may relate to the development and maintenance of SUD differently at various stages in the process (e.g., [87]) and at various developmental periods (e.g., $[22,57 \cdot])$. Furthermore, the use of substances at a critical period in development may have implications for the functioning of these systems (e.g., [27•]; also see reviews in [88-91]) and the likelihood of transitioning into problem use. The perennial challenge, then, is disentangling relationships among risk, substance use, and neurodevelopment.

In recent years, there has been an emergence of longitudinal studies, which allow for powerful prospective approaches to identifying age-specific risk factors and enable characterization of neural systems and emerging substance use and problems in parallel. Additionally, large-scale, multi-site longitudinal studies are allowing for multivariate analyses across a vast range of risk factors to enable broader inferences (e.g., $[30,31 \bullet \cdot])$. Much of this work begins with baseline assessment in early adolescence, which has the likely advantage of capturing emerging substance use within a 5-year period, due to normative increases in use throughout adolescence. A limitation, however, is that youth at the highest risk for SUD have already initiated substance use by early adolescence. Research indicates that substance use by age 13 substantially increases risk for later dependence [4, 5]; thus, longitudinal studies targeting high-risk populations some years prior to this age and following them through adolescence into early adulthood are critical. Furthermore, much of the work reviewed here did not explore gender differences. While rates of past-year SUD in 12-17-year olds are equal between males and females (6.1\%), a significant gender divergence emerges afterward, with higher rates in males aged 18 or older $(12.2 \%)$, 
compared with females (5.7\%) [86]. An understanding of how gender differences in brain development and functioning may contribute to differential risk for SUD will be an important future focus of research.

Findings of moderating effects of family history (e.g., [52, 68]) and gender (e.g., [75••]) illustrate heterogeneity in the relationship between brain function and risk for SUD and highlight the importance of investigating potential moderating and mediating influences that may impact outcome. These include not only a high-risk genetic background marked by family history [92, 93] but also poor parenting [94], stress [95], conflict in the home [96], and peer involvement [97]. For example, recent work has illustrated a moderating effect of the presence of peers on adolescent risk taking, and mediation of this effect by functioning of reward-related circuitry, as well as developmental impacts on the effect $[98,99]$. This has not yet been investigated in the specific context of SUD risk. A thorough developmental understanding of vulnerability pathways will require longitudinal characterization of influences across multiple levels, including environmental and social contexts, gender, behavior, neural functioning, and genetics. Knowledge of how these complex systems interact to provide developmental periods of increased or decreased vulnerability has the potential to guide the type and timing of interventions for at-risk individuals to improve outcomes.

Acknowledgments During manuscript preparation, Dr. Cope was supported by T32 DA007268, and Dr. Hardee and Ms. Martz were supported by T32 DA007267.

\section{Compliance with Ethics Guidelines}

Conflict of Interest Mary M. Heitzeg, Lora M. Cope, Meghan E. Martz, and Jillian E. Hardee declare that they have no conflict of interest.

Human and Animal Rights and Informed Consent This article does not contain any studies with human or animal subjects performed by any of the authors.

\section{References}

Papers of particular interest, published recently, have been highlighted as:

- Of importance

•- Of major importance

1. D'Amico EJ, Ellickson PL, Collins RL, Martino S, Klein DJ. Processes linking adolescent problems to substance-use problems in late young adulthood. J Stud Alcohol. 2005;66:766-75.

2. Johnston LD, O’Malley PM, Bachman JG, Schulenberg JE, Miech RA. Monitoring the future: national survey results on drug use, 1975-2013: volume 1, secondary school students. Ann Arbor: Institute for Social Research, The University of Michigan; 2014.

3. Ellickson PL, McCaffrey DF, Ghosh-Dastidar B, Longshore DL. New inroads in preventing adolescent drug use: results from a large- scale trial of project ALERT in middle schools. Am J Public Health. 2003;93:1830-6.

4. Grant BF, Dawson DA. Age at onset of alcohol use and its association with DSM-IV alcohol abuse and dependence: results from the National Longitudinal Alcohol Epidemiologic Survey. J Subst Abus. 1997;9:103-10.

5. Grant BF, Dawson DA. Age of onset of drug use and its association with DSM-IV drug abuse and dependence: results from the National Longitudinal Alcohol Epidemiologic Survey. J Subst Abus. 1998;10:163-73.

6. Gmel G, Rehm J. Harmful alcohol use. Alcohol Res Health. 2003;27:52-62.

7. Rehm J, Gmel G, Sempos CT, Trevisan M. Alcohol-related morbidity and mortality. Alcohol Res Health. 2003;27:39-51.

8. Rehm J, Room R, Monteiro M, Gmel G, Graham K, et al. Alcohol as a risk factor for global burden of disease. Eur Addict Res. 2003;9:157-64.

9. Eisenberg N, Guthrie IK, Fabes RA, Reiser M, Murphy BC, et al. The relations of regulation and emotionality to resiliency and competent social functioning in elementary school children. Child Dev. 1997;68:295-311.

10. Nigg JT. On inhibition/disinhibition in developmental psychopathology: views from cognitive and personality psychology and a working inhibition taxonomy. Psychol Bull. 2000;126:220-46.

11. Zucker RA, Heitzeg MM, Nigg JT. Parsing the undercontrol/ disinhibition pathway to substance use disorders: a multilevel developmental problem. Child Dev Perspect. 2011;5:248-55.

12. Young SE, Friedman NP, Miyake A, Willcutt EG, Corley RP, et al. Behavioral disinhibition: liability for externalizing spectrum disorders and its genetic and environmental relation to response inhibition across adolescence. J Abnorm Psychol. 2009;118:117-30.

13. Wills TA, Vaccaro D, McNamara G, Hirky AE. Escalated substance use: a longitudinal grouping analysis from early to middle adolescence. J Abnorm Psychol. 1996;105:166-80.

14. Miller P, Plant M. Heavy cannabis use among UK teenagers: an exploration. Drug Alcohol Depend. 2002;65:235-42.

15. Rohde P, Lewinsohn PM, Seeley JR. Psychiatric comorbidity with problematic alcohol use in high school students. J Am Acad Child Adolesc Psychiatry. 1996;35:101-9.

16. Silveri MM, Rogowska J, McCaffrey A, Yurgelun-Todd DA. Adolescents at risk for alcohol abuse demonstrate altered frontal lobe activation during Stroop performance. Alcohol Clin Exp Res. 2011;35:218-28.

17. McNamee RL, Dunfee KL, Luna B, Clark DB, Eddy WF, et al. Brain activation, response inhibition, and increased risk for substance use disorder. Alcohol Clin Exp Res. 2008;32:405-13.

18. Schweinsburg AD, Paulus MP, Barlett VC, Killeen LA, Caldwell LC, et al. An FMRI study of response inhibition in youths with a family history of alcoholism. Ann N Y Acad Sci. 2004;1021:391-4.

19. Heitzeg MM, Nigg JT, Yau WY, Zucker RA, Zubieta JK. Striatal dysfunction marks preexisting risk and medial prefrontal dysfunction is related to problem drinking in children of alcoholics. Biol Psychiatry. 2010;68:287-95.

20. Tottenham N, Hare TA, Casey BJ. Behavioral assessment of emotion discrimination, emotion regulation, and cognitive control in childhood, adolescence, and adulthood. Front Psychol. 2011;2:39.

21. Rubia K, Smith AB, Woolley J, Nosarti C, Heyman I, et al. Progressive increase of frontostriatal brain activation from childhood to adulthood during event-related tasks of cognitive control. Hum Brain Mapp. 2006;27:973-93.

22. Hardee JE, Weiland BJ, Nichols TE, Welsh RC, Soules ME, et al. Development of impulse control circuitry in children of alcoholics. Biol Psychiatry. 2014;76:708-16.

23. Norman AL, Pulido C, Squeglia LM, Spadoni AD, Paulus MP, et al. Neural activation during inhibition predicts initiation of substance use in adolescence. Drug Alcohol Depend. 2011;119:216-23. This 
is the first prospective study demonstrating that early inhibitory functioning in youth with little or no substance use may predict later initiation of heavy drinking. This work moves the field beyond investigating neural risk factors based on expected outcomes inferred by family history or other measures and provides a more definitive link between early brain functioning and later outcomes.

24. Mahmood OM, Goldenberg D, Thayer R, Migliorini R, Simmons AN, et al. Adolescents' fMRI activation to a response inhibition task predicts future substance use. Addict Behav. 2013;38:143541.

25. Grabner RH, Ansari D, Reishofer G, Stern E, Ebner F, et al. Individual differences in mathematical competence predict parietal brain activation during mental calculation. Neuroimage. 2007;38: 346-56.

26. Hartwigsen G, Baumgaertner A, Price CJ, Koehnke M, Ulmer S, et al. Phonological decisions require both the left and right supramarginal gyri. Proc Natl Acad Sci U S A. 2010;107:16494-9.

27. Wetherill RR, Squeglia LM, Yang TT, Tapert SF. A longitudinal examination of adolescent response inhibition: neural differences before and after the initiation of heavy drinking. Psychopharmacology (Berl). 2013;230:663-71. This longitudinal study is the first to examine differences in response inhibition circuitry functioning before and after heavy substance use in adolescence. The novel finding of blunted activation prior to and heightened activation following heavy use are a first step to disentangling preexisting risk for effects of substance use in the brain.

28. Ridderinkhof KR, Ullsperger M, Crone EA, Nieuwenhuis S. The role of the medial frontal cortex in cognitive control. Science. 2004;306:443-7.

29. Heitzeg MM, Nigg JT, Hardee JE, Soules M, Steinberg D, et al. Left middle frontal gyrus response to inhibitory errors in children prospectively predicts early problem substance use. Drug Alcohol Depend. 2014;141:51-7.

30. Schumann G, Loth E, Banaschewski T, Barbot A, Barker G, et al. The IMAGEN study: reinforcement-related behaviour in normal brain function and psychopathology. Mol Psychiatry. 2010;15: $1128-39$.

31.•Whelan R, Watts R, Orr CA, Althoff RR, Artiges E, et al. Neuropsychosocial profiles of current and future adolescent alcohol misusers. Nature. 2014;512:185-9. This paper presents a generalizable risk profile for prediction of binge drinking using data from a large-scale, multi-site longitudinal study. Using machine learning, models of risk were generated incorporating a broad range of factors including personality, life experience, cognition, genetics, brain structure, and brain function. Of particular significance in this work is the rigorous methodology, which included cross-validation and replication.

32. Braet W, Johnson KA, Tobin CT, Acheson R, McDonnell C, et al. fMRI activation during response inhibition and error processing: the role of the DAT1 gene in typically developing adolescents and those diagnosed with ADHD. Neuropsychologia. 2011;49:164150 .

33. Cummins TD, Hawi Z, Hocking J, Strudwick M, Hester R, et al. Dopamine transporter genotype predicts behavioural and neural measures of response inhibition. Mol Psychiatry. 2012;17:1086-92.

34. Congdon E, Canli T. A neurogenetic approach to impulsivity. J Pers. 2008;76:1447-84.

35. Erblich J, Lerman C, Self DW, Diaz GA, Bovbjerg DH. Stressinduced cigarette craving: effects of the DRD2 TaqI RFLP and SLC6A3 VNTR polymorphisms. Pharmacogenomics J. 2004;4: $102-9$.

36. Devito EE, Meda SA, Jiantonio R, Potenza MN, Krystal JH, et al. Neural correlates of impulsivity in healthy males and females with family histories of alcoholism. Neuropsychopharmacology. 2013;38:1854-63.

37. Steinberg L. A social neuroscience perspective on adolescent risktaking. Dev Rev. 2008;28:78-106.

38. Spear LP. Rewards, aversions and affect in adolescence: emerging convergences across laboratory animal and human data. Dev Cogn Neurosci. 2011;1:390-403.

39. Schultz W. Predictive reward signal of dopamine neurons. J Neurophysiol. 1998;80:1-27.

40. Robinson TE, Berridge KC. The psychology and neurobiology of addiction: an incentive- sensitization view. Addiction. 2000;95 Suppl 2:S91-S117.

41. Piazza PV, Rouge-Pont F, Deminiere JM, Kharoubi M, Le Moal M, et al. Dopaminergic activity is reduced in the prefrontal cortex and increased in the nucleus accumbens of rats predisposed to develop amphetamine self-administration. Brain Res. 1991;567:169-74.

42. Volkow ND, Wang GJ, Maynard L, Fowler JS, Jayne B, et al. Effects of alcohol detoxification on dopamine D2 receptors in alcoholics: a preliminary study. Psychiatry Res. 2002;116:163-72.

43. McBride WJ, Li TK. Animal models of alcoholism: neurobiology of high alcohol-drinking behavior in rodents. Crit Rev Neurobiol. 1998;12:339-69.

44. Hariri AR, Brown SM, Williamson DE, Flory JD, de Wit H, et al. Preference for immediate over delayed rewards is associated with magnitude of ventral striatal activity. J Neurosci. 2006;26:13213-7.

45. McClure SM, Laibson DI, Loewenstein G, Cohen JD. Separate neural systems value immediate and delayed monetary rewards. Science. 2004;306:503-7.

46. Blum K, Braverman ER, Holder JM, Lubar JF, Monastra VJ, et al. Reward deficiency syndrome: a biogenetic model for the diagnosis and treatment of impulsive, addictive, and compulsive behaviors. J Psychoactive Drugs. 2000;32(Suppl):i-iv. 1-112.

47. Stice E, Yokum S. Brain reward region responsivity of adolescents with and without parental substance use disorders. Psychol Addict Behav. 2014;28:805-15.

48. Boileau I, Dagher A, Leyton M, Gunn RN, Baker GB, et al. Modeling sensitization to stimulants in humans: an [11C]raclopride/positron emission tomography study in healthy men. Arch Gen Psychiatry. 2006;63:1386-95.

49. Nocjar C, Panksepp J. Prior morphine experience induces longterm increases in social interest and in appetitive behavior for natural reward. Behav Brain Res. 2007;181:191-9.

50. Chassin L, Pitts SC, DeLucia C, Todd M. A longitudinal study of children of alcoholics: predicting young adult substance use disorders, anxiety, and depression. J Abnorm Psychol. 1999;108:10619.

51. Sher KJ, Walitzer KS, Wood PK, Brent EE. Characteristics of children of alcoholics: putative risk factors, substance use and abuse, and psychopathology. J Abnorm Psychol. 1991;100:427-48.

52. Yau WY, Zubieta JK, Weiland BJ, Samudra PG, Zucker RA, et al. Nucleus accumbens response to incentive stimuli anticipation in children of alcoholics: relationships with precursive behavioral risk and lifetime alcohol use. J Neurosci. 2012;32:2544-51.

53. Knutson B, Fong GW, Adams CM, Varner JL, Hommer D. Dissociation of reward anticipation and outcome with eventrelated fMRI. Neuroreport. 2001;12:3683-7.

54. Knutson B, Adams CM, Fong GW, Hommer D. Anticipation of increasing monetary reward selectively recruits nucleus accumbens. J Neurosci. 2001;21:RC159.

55. Muller KU, Gan G, Banaschewski T, Barker GJ, Bokde AL, et al. No differences in ventral striatum responsivity between adolescents with a positive family history of alcoholism and controls. Addict Biol. 2014; Advance online publication. doi:10.1111/adb.12136.

56. Bjork JM, Knutson B, Hommer DW. Incentive-elicited striatal activation in adolescent children of alcoholics. Addiction. 2008;103: 1308-19. 
57. Heitzeg MM, Villafuerte S, Weiland BJ, Enoch MA, Burmeister M, et al. Effect of GABRA2 genotype on development of incentivemotivation circuitry in a sample enriched for alcoholism risk. Neuropsychopharmacology. 2014;39:3077-86. This is the first demonstration that risk-related differences in reward system responsivity may be developmentally modulated. Importantly, this was demonstrated within-subjects using a longitudinal design.

58. Olson EA, Collins PF, Hooper CJ, Muetzel R, Lim KO, et al. White matter integrity predicts delay discounting behavior in 9- to 23year-olds: a diffusion tensor imaging study. J Cogn Neurosci. 2009;21:1406-21.

59. Olson EA, Hooper CJ, Collins P, Luciana M. Adolescents' performance on delay and probability discounting tasks: contributions of age, intelligence, executive functioning, and self-reported externalizing behavior. Personal Individ Differ. 2007;43:1886-97.

60. Scheres A, Dijkstra M, Ainslie E, Balkan J, Reynolds B, et al. Temporal and probabilistic discounting of rewards in children and adolescents: effects of age and ADHD symptoms. Neuropsychologia. 2006;44:2092-103.

61. Steinberg L, Graham S, O'Brien L, Woolard J, Cauffman E, et al. Age differences in future orientation and delay discounting. Child Dev. 2009;80:28-44.

62. Steinberg L. A dual systems model of adolescent risk-taking. Dev Psychobiol. 2010;52:216-24

63. Casey BJ, Getz S, Galvan A. The adolescent brain. Dev Rev. 2008;28:62-77.

64. Ivanov I, Liu X, Shulz K, Fan J, London E, et al. Parental substance abuse and function of the motivation and behavioral inhibition systems in drug-naive youth. Psychiatry Res. 2012;201:128-35.

65. Cservenka A, Nagel BJ. Risky decision-making: an FMRI study of youth at high risk for alcoholism. Alcohol Clin Exp Res. 2012;36: 604-15.

66. Ernst M, Nelson EE, McClure EB, Monk CS, Munson S, et al. Choice selection and reward anticipation: an fMRI study. Neuropsychologia. 2004;42:1585-97.

67. Cservenka A, Casimo K, Fair DA, Nagel BJ. Resting state functional connectivity of the nucleus accumbens in youth with a family history of alcoholism. Psychiatry Res. 2014;221:210-9.

68. Weiland BJ, Welsh RC, Yau WY, Zucker RA, Zubieta JK, et al. Accumbens functional connectivity during reward mediates sensation-seeking and alcohol use in high-risk youth. Drug Alcohol Depend. 2013;128:130-9.

69. Yacubian J, Sommer T, Schroeder K, Glascher J, Kalisch R, et al. Gene-gene interaction associated with neural reward sensitivity. Proc Natl Acad Sci U S A. 2007;104:8125-30.

70. Camara E, Kramer UM, Cunillera T, Marco-Pallares J, Cucurell D, et al. The effects of COMT (Val108/158Met) and DRD4 (SNP 521) dopamine genotypes on brain activations related to valence and magnitude of rewards. Cereb Cortex. 2010;20:1985-96.

71. Dreher JC, Kohn P, Kolachana B, Weinberger DR, Berman KF. Variation in dopamine genes influences responsivity of the human reward system. Proc Natl Acad Sci U S A. 2009;106:617-22.

72. Forbes EE, Brown SM, Kimak M, Ferrell RE, Manuck SB, et al. Genetic variation in components of dopamine neurotransmission impacts ventral striatal reactivity associated with impulsivity. Mol Psychiatry. 2009;14:60-70.

73. Rada P, Mark GP, Hoebel BG. Galanin in the hypothalamus raises dopamine and lowers acetylcholine release in the nucleus accumbens: a possible mechanism for hypothalamic initiation of feeding behavior. Brain Res. 1998;798:1-6.

74. Rada P, Avena NM, Leibowitz SF, Hoebel BG. Ethanol intake is increased by injection of galanin in the paraventricular nucleus and reduced by a galanin antagonist. Alcohol. 2004;33:91-7.

75.•• Nikolova YS, Singhi EK, Drabant EM, Hariri AR. Reward-related ventral striatum reactivity mediates gender-specific effects of a galanin remote enhancer haplotype on problem drinking. Genes Brain Behav. 2013;12:516-24. This is one of very few studies to investigate gender differences in genetic and neural risk factors that may underlie risk for problem substance use. Results suggest different pathways involved in risk for males and females.

76. Villafuerte S, Heitzeg MM, Foley S, Yau WY, Majczenko K, et al Impulsiveness and insula activation during reward anticipation are associated with genetic variants in GABRA2 in a family sample enriched for alcoholism. Mol Psychiatry. 2012;17:511-9.

77. Schwarzer C, Berresheim U, Pirker S, Wieselthaler A, Fuchs K, et al. Distribution of the major gamma-aminobutyric acid(A) receptor subunits in the basal ganglia and associated limbic brain areas of the adult rat. J Comp Neurol. 2001;433:526-49.

78. Steffensen SC, Svingos AL, Pickel VM, Henriksen SJ. Electrophysiological characterization of GABAergic neurons in the ventral tegmental area. J Neurosci. 1998;18:8003-15.

79. Edenberg HJ, Dick DM, Xuei X, Tian H, Almasy L, et al. Variations in GABRA2, encoding the alpha 2 subunit of the GABA(A) receptor, are associated with alcohol dependence and with brain oscillations. Am J Hum Genet. 2004;74:705-14.

80. Covault J, Gelernter J, Hesselbrock V, Nellissery M, Kranzler HR Allelic and haplotypic association of GABRA2 with alcohol dependence. Am J Med Genet B Neuropsychiatr Genet. 2004;129B:104-9.

81. Dick DM, Latendresse SJ, Lansford JE, Budde JP, Goate A, et al. Role of GABRA2 in trajectories of externalizing behavior across development and evidence of moderation by parental monitoring. Arch Gen Psychiatry. 2009;66:649-57.

82. Dager AD, Anderson BM, Rosen R, Khadka S, Sawyer B, et al. Functional magnetic resonance imaging (fMRI) response to alcohol pictures predicts subsequent transition to heavy drinking in college students. Addiction. 2014;109:585-95.

83. Schacht JP, Anton RF, Myrick H. Functional neuroimaging studies of alcohol cue reactivity: a quantitative meta-analysis and systematic review. Addict Biol. 2013;18:121-33.

84. Volkow ND, Wang GJ, Fowler JS, Tomasi D, Telang F. Addiction: beyond dopamine reward circuitry. Proc Natl Acad Sci U S A. 2011;108:15037-42.

85. Harford TC, Grant BF, Yi HY, Chen CM. Patterns of DSM-IV alcohol abuse and dependence criteria among adolescents and adults: results from the 2001 National Household Survey on Drug Abuse. Alcohol Clin Exp Res. 2005;29:810-28.

86. Substance Abuse and Mental Health Services Administration. Results from the 2012 National Survey on Drug Use and Health: Summary of National Findings. NSDUH Series H-46, HHS Pub. No. SMA 13-4795. Rockville: Substance Abuse and Mental Health Services Administration; 2013.

87. Hommer DW, Bjork JM, Gilman JM. Imaging brain response to reward in addictive disorders. Ann N Y Acad Sci. 2011;1216:50-61.

88. Lisdahl KM, Gilbart ER, Wright NE, Shollenbarger S. Dare to delay? The impacts of adolescent alcohol and marijuana use onset on cognition, brain structure, and function. Front Psychiatry. 2013;4:53.

89. Lisdahl KM, Wright NE, Kirchner-Medina C, Maple KE, Shollenbarger S. Considering Cannabis: the effects of regular cannabis use on neurocognition in adolescents and young adults. Curr Addict Rep. 2014;1:144-56.

90. Jacobus J, Tapert SF. Neurotoxic effects of alcohol in adolescence. Annu Rev Clin Psychol. 2013;9:703-21.

91. Squeglia LM, Jacobus J, Tapert SF. The effect of alcohol use on human adolescent brain structures and systems. Handb Clin Neurol. 2014;125:501-10.

92. Goodwin DW. The genetics of alcoholism. Hosp Community Psychiatry. 1983;34:1031-4.

93. Goodwin DW. Familial alcoholism: a separate entity? Subst Alcohol Actions Misuse. 1983;4:129-36. 
94. Olson SL, Bates JE, Bayles K. Early antecedents of childhood impulsivity: the role of parent-child interaction, cognitive competence, and temperament. J Abnorm Child Psychol. 1990;18:31734.

95. Spear LP. The adolescent brain and the college drinker: biological basis of propensity to use and misuse alcohol. J Stud Alcohol Suppl. $2002 ; 71-81$.

96. Hussong A, Bauer D, Chassin L. Telescoped trajectories from alcohol initiation to disorder in children of alcoholic parents. J Abnorm Psychol. 2008;117:63-78.
97. Dielman TE, Butchart AT, Shope JT. Structural equation model tests of patterns of family interaction, peer alcohol use, and intrapersonal predictors of adolescent alcohol use and misuse. J Drug Educ. 1993;23:273-316.

98. Chein J, Albert D, O'Brien L, Uckert K, Steinberg L. Peers increase adolescent risk taking by enhancing activity in the brain's reward circuitry. Dev Sci. 2011;14:F1-F10.

99. Smith AR, Steinberg L, Strang N, Chein J. Age differences in the impact of peers on adolescents' and adults' neural response to reward. Dev Cogn Neurosci. 2015;11:75-82. 